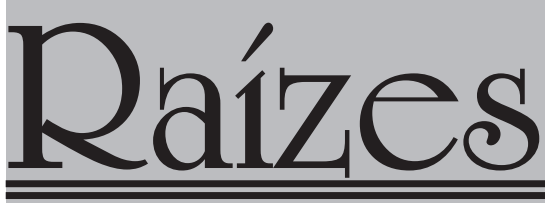

v.33, n.2, jul-dez /2013

\title{
A RECIPROCIDADE NAS ORGANIZAÇÕES DOS AGRICULTORES FAMILIARES EM COMUNIDADES RURAIS NO NORDESTE DO PARÁ ${ }^{1}$
}

\author{
Glaucia Macedo Sousa, Heribert Schmitz, Dalva Maria da Mota
}

\section{RESUMO}

O objetivo do artigo é analisar as relações de reciprocidade entre os participantes de organizações dos agricultores familiares no Nordeste do Pará. A pesquisa foi realizada por meio de um estudo de caso em uma das comunidades do Assentamento Itabocal, Santa Ana, Município de Mãe do Rio. Os métodos constaram de entrevistas e observações dos eventos cooperativos, festivos e religiosos do grupo. As conclusões mostram que as organizações analisadas estimulam relações que abarcam as três etapas da reciprocidade: dar, receber e retribuir. No entanto, essa identificação somente é possível quando se leva em consideração não só a circulação de bens materiais (instrumentos agrícolas), simbólicos (palavras, prestígio, amizade, etc.) e de trabalho entre as pessoas, mas também a relação entre elas e as suas divindades (Deus e Santa Ana).

Palavras-Chave: Dádiva. Agricultura Familiar. Organizações Comunitárias.

\section{RECIPROCITY IN FAMILY FARMER ORGANIZATIONS OF RURAL COMMUNITIES IN THE NORTHEAST OF THE STATE OF PARÁ, BRAZIL}

\section{ABSTRACT}

This paper analyses the reciprocal relationships among family farmer organizations members in the Northeast of the state of Pará. A case study was carried out in the Santa Ana Community, Itabocal Land Settlement, located in the Municipality of Mãe do Rio, in Northeast Pará. Structured, semi-structured and open interviews were accomplished followed by observation in cooperative, festive and religious events. Results show that the assessed organizations stimulate relationships that comprise the three phases of reciprocity: giving, receiving and reciprocating. This identification is possible, however, only when one takes into account the circulation of material goods (agricultural tools), symbolic goods (words, prestige, friendship, etc.) and work relationships among people, but also between people and their deities (God and Santa Ana).

Keywords: Gift. Family Farming. Community Organizations.

Mestre em Ciências Sociais; PPGCS/UFPA, Belém-PA. E-mail: glauciarusso@ymail.com.

Doutor em Sociologia Rural, professor de Sociologia da UFPA, Belém-PA, bolsista de produtividade do CNPq. E-mail: heri@zedat.fu-berlin.de. Doutora em Sociologia, pesquisadora da Embrapa Amazônia Oriental, Belém-PA, bolsista de produtividade do CNPq. E-mail: dalva.mota@embrapa.br.

1 Pesquisa realizada com aporte financeiro do CNPq.

Raízes, v.33, n.2, jul-dez /2013 
INTRODUÇÃO

Inspirados nos escritos de Marcel Mauss (1974 [1950]), autores como Godbout (2000), Caillé (1998) e Sabourin (2009) têm refletido sobre a temática da reciprocidade. Em geral, eles analisam que na vida social atual existem relações que privilegiam outras formas de interesses, os quais são baseados na construção de laços de amizade, prestígio social, confiança e outros valores. Enfatizando ainda mais a importância do tema, Caillé (1998) sugere que a reciprocidade seja reconhecida como um novo paradigma para as ciências sociais, assim como o holismo e o individualismo metodológico já o são.

Godbout (2000) indica a existência de uma reciprocidade desinteressada, caracterizada por doações gratuitas e generosas que dispensam a retribuição, as quais são vivenciadas entre pessoas que não se conhecem e que, por isso, ficam impossibilitadas de alimentar a relação em torno da retribuição da dádiva recebida. Esse é o caso das doações para transplante de órgãos, da filantropia e das esmolas.

No espaço rural, Caldeiras (1956) identificou na região do Rio Doce, no Estado do Espírito Santo, a reciprocidade desinteressada, sem retorno, entre desconhecidos, visto que certos doadores eram nômades e, por isso, não tinham a previsão nem possibilidade de receber a retribuição ${ }^{2}$. Nessa mesma perspectiva, mas entre conhecidos, Sabourin analisou a existência da reciprocidade sem retorno "no caso de uma colheita ruim, doença ou acidente em uma das famílias" em várias regiões do Brasil (Sabourin, 2009, p. 52).
No Pará, mais especificamente na região de Marabá, Veiga e Albaladejo (2002) identificaram "os mutirões para os doentes", cujo objetivo era ajudar a família de agricultores com problemas de saúde, sem deixar de prever a reciprocidade da ajuda concedida em momentos semelhantes de fragilidade.

Tendo em conta as diferentes análises que tratam da obrigatoriedade ou não da reciprocidade, nos interessa analisar neste artigo se a reciprocidade é vivenciada por meio de doações gratuitas, ou seja, com a ausência da retribuição, ou com recompensas à generosidade nas relações tecidas entre os afiliados à organizações de homens e mulheres autodesignados como lavradores e agricultores familiares. $\mathrm{O}$ estudo do fenômeno nos chamou a atenção pelo fato de todas as organizações terem sido estimuladas pela Igreja Católica segundo o princípio de que "é dando que se recebe".

Entendemos neste artigo a reciprocidade como sinônimo de dádiva caracterizada pela circulação (dar, receber e retribuir) de presentes, palavras, gestos que são capazes de gerar vínculos sociais entre as coletividades e as pessoas. Embora estimule a produção e a sobrevivência da família, nesse tipo de relação, mais do que garantir bens materiais, os indivíduos agem para salvaguardar sua situação social (Polanyi, 2000 [1944]).

Nas reflexões sobre a reciprocidade é comum a contraposição aos argumentos do individualismo metodológico que define as relações sociais como relações balizadas fundamentalmente a partir de interesse econômico. Segundo essa perspectiva, cujo autor de referência é Mancur Olson (1998), as pessoas agem a

2 Ver sobre o ato desinteressado também em Bourdieu (1996a; 1996b, p. 137-156) e Zaluar (1997). 
partir de um cálculo econômico visando maximizar ganhos econômicos e minimizar custos, produzindo indivíduos oportunistas (free rider) que evitam aplicar esforços cooperativos, porém esperam usufruir dos benefícios.

Para tratar do tema, realizamos um estudo de caso na Comunidade Santa $\mathrm{Ana}^{3}$ do Piripindeua, localizada no assentamento de reforma agrária Itabocal ${ }^{4}$ no Município de Mãe do Rio, Nordeste Paraense (FIGURA 1). A metodologia, amparada na sociologia rural e na antropologia social, constou de observação direta e participante e de entrevistas (abertas, semiestruturadas e estruturadas), realizadas no período de 2009 a 2013. Os atores privilegiados na pesquisa foram homens e mulheres que praticam a agricultura de base familiar, foram estimulados a se organizar a partir dos preceitos da religião católica e mantêm em pleno funcionamento as suas organizações por, pelo menos, quatro décadas.
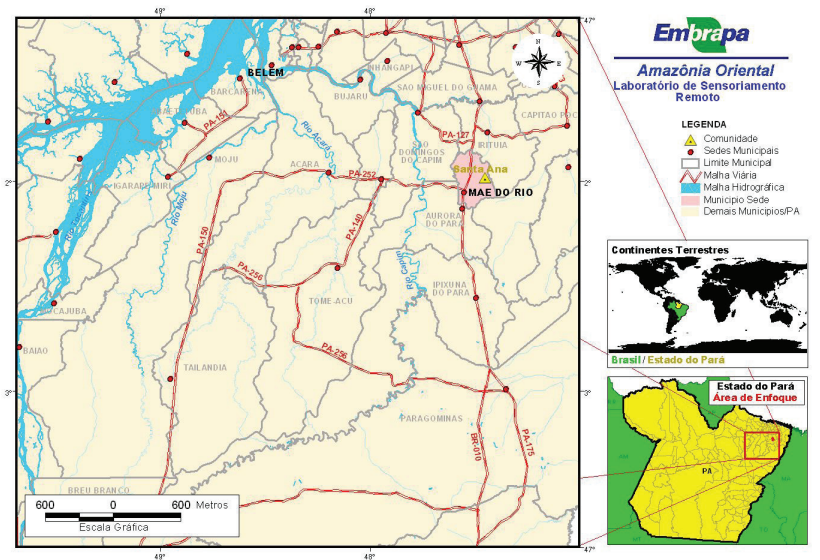

FIGURA 1- Localização da Comunidade Santa Ana, Mãe do Rio, PA.

\section{REGULARIZAÇÃO FUNDIÁRIA: REFOR- MA AGRÁRIA ÀS "AVESSAS"?}

A reforma agrária "às avessas", aqui tomada como uma evidência da ação tardia do Estado na Amazônia Brasileira para o reconhecimento e, consequente, regularização fundiária da terra ocupada pelos camponeses há décadas, foi o modo como os agricultores da Comunidade Santa Ana vivenciaram o acesso à terra. Em resposta, reconstruíram o sentido das ações subsequentes à regularização fundiária e as enquadraram na categoria "projeto", algo externo que implica no acesso a outros serviços e bens que não mais a terra (Magalhães, 2003).

Assim, três tempos demarcam a história do grupo. O "tempo dos antigos", dos conflitos e dos projetos. Esses tempos têm referência na literatura, sendo o primeiro tratado por Hurtienne (1999) como marcado pela forte presença de extrativistas tradicionais e agricultores itinerantes, grupos indígenas, caboclos e ribeirinhos e por Velho (1979) como um campesinato migrante do Nordeste e oriundo da falência da economia da borracha. Em ambos os casos, a agricultura de "derruba e queima" (agricultura itinerante) sustenta a produção, especificamente na região do Nordeste Paraense. O tempo dos conflitos conforma-se após a construção da Estrada Belém-Brasília e a consequente valorização da terra, no início da década de 1970. Em torno da posse, instituiu-se uma disputa com um fazendeiro. Os agricultores contaram com o apoio das Comunidades Eclesiais

\footnotetext{
3 Padroeira da comunidade e conhecida pela tradição católica como a Mãe de Santa Maria e avó de Jesus Cristo. O dia de Santa Ana é comemorado todo dia 26 de julho.

$4 \mathrm{O}$ assentamento Itabocal alcança três municípios paraenses, quais sejam: Mãe do Rio, Irituia e Capitão Poço e comporta 27 comunidades. Com uma dimensão de 26.192 hectares, é muito diferente dos demais assentamentos de outras regiões do Brasil. Ali existem três tipos de "assentados": a) Posseiros de ocupação antiga que já viviam no lugar desde os anos 1940. O assentamento, neste caso significou, principalmente, a regularização fundiária e o acesso a serviços, como aconteceu também em outras regiões da Amazônia; b) Posseiros de ocupação recente nos anos 1980; e) Assentados levados pelo INCRA para o assentamento no momento da fundação oficial.
} 
de Base (CEBs) e do Sindicato dos Trabalhadores Rurais (STR), sendo que o fim desse processo ocorreu somente nos anos de $1990 \mathrm{com}$ a desapropriação da terra e demarcação do assentamento. O tempo dos projetos é subsequente à regularização fundiária, quando, em atendimento aos preceitos da reforma agrária, as áreas familiares foram subdivididas em "lotes" e, na condição de assentadas, as famílias tiveram acesso aos créditos agrícola e de habitação. Ademais, tiveram "tranquilidade" quanto ao acesso à terra.

Nos meios de vida dos agricultores, evidencia-se a organização do trabalho por meio da associação família-produção-trabalho, característica central do campesinato, conforme indicam Chayanov (1981) e Mendras (1978). Ademais, destacamos a valorização da família como unidade de apoio para onde convergem os rendimentos, além do sentimento de religiosidade que integra as pessoas na Igreja Católica, estabelecida na região desde a década de 1950, ou na Assembleia de Deus, atuante no lugar desde 1970.

A vida associativa é propagada, principalmente pela valorização da participação nas diferentes organizações locais que podem ser demarcadas em dois grupos (Quadro 1). O primeiro grupo formado pelas organizações cuja fundação foi estimulada pela Igreja Católica. São eles a Coordenação da Comunidade, o Clube Agrícola e o Clube de Mães, fundados no ano de 1960, e a Coordenação Regional, criada há cerca de dez anos. O segundo é formado pela Associação Integrada de Piripindeua, iniciativa estimulada pelo Estado como pré-requisito para o acesso às políticas públicas após a regularização do acesso à terra nos anos 1990.
Quadro 1- ORIENTAÇÃo Religiosa E FUnCIONAMENTO DAS ORGanizaÇÕES EM SANTA ANA, PA.

\begin{tabular}{|c|c|c|}
\hline Católicos & Evangélicos & \multicolumn{1}{|c|}{ Funcionamento } \\
\hline $\begin{array}{l}\text { Coordenação } \\
\text { Regional }\end{array}$ & - & $\begin{array}{l}\text { Promove encontros quin- } \\
\text { zenais entre agricultores de } \\
\text { Santa Ana e aqueles que fi- } \\
\text { cavam ao entorno da região } \\
\text { para a cooperação, para re- } \\
\text { alizar festas religiosas e aju- } \\
\text { dar as pessoas que passa- } \\
\text { vam por dificuldades. }\end{array}$ \\
\hline $\begin{array}{l}\text { Conselho da } \\
\text { Comunidade }\end{array}$ & - & $\begin{array}{l}\text { Reúne de 15 em 15 dias as } \\
\text { lideranças para discutir os } \\
\text { problemas locais e propor } \\
\text { soluções. }\end{array}$ \\
\hline $\begin{array}{l}\text { Clube de } \\
\text { Mães }\end{array}$ & - & $\begin{array}{l}\text { Reúne as mulheres da lo- } \\
\text { calidade para organizar os } \\
\text { principais eventos festivos, } \\
\text { dentre os quais a festa de } \\
\text { Santa Ana. }\end{array}$ \\
\hline $\begin{array}{l}\text { Clube } \\
\text { Agrícola }\end{array}$ & - & $\begin{array}{l}\text { As quartas-feiras os parti- } \\
\text { cipantes eram mobilizados } \\
\text { para realizar atividades vol- } \\
\text { tadas para a agricultura. }\end{array}$ \\
\hline \multicolumn{2}{|c|}{$\begin{array}{l}\text { Associação Integrada de } \\
\text { Piripindeua }\end{array}$} & $\begin{array}{l}\text { Reúne-se ocasionalmente } \\
\text { quando há demanda exter- } \\
\text { na dos órgãos públicos. }\end{array}$ \\
\hline
\end{tabular}

Fonte: pesquisa de campo.

O fato das organizações do primeiro grupo terem sido estimuladas pela Igreja Católica explica a ausência dos evangélicos, que optaram por participar somente da associação, uma vez que esta não tem viés religioso. Como neste caso as ações são estimuladas apenas para acessar benefícios oriundos de programas de políticas públicas, a ação coletiva ocorre ocasionalmente. Ao contrário, nas organizações estimuladas pela Igreja Católica, existe uma maior intensidade de iniciativas cooperativas com encontros semanais sistemáticos independentemente de estímulos externos.

Para o funcionamento das organizações locais, existe a presença de um "notável" ou "mediador" (Mendras, 1978), liderança responsável por representar a comunidade diante 
dos que chegam e por fazer as negociações necessárias com organizações prestadoras de serviços (assistência técnica, pesquisa, ação social, políticas públicas) no assentamento. Na história recente, identificamos a trajetória de dois notáveis. O primeiro atuou entre 1950 e 1987, fora legitimado pelos critérios da Igreja Católica, que em um contexto de analfabetismo optou por um agricultor alfabetizado a quem foi atribuído o papel de "coordenador da comunidade", cargo de maior importância no Conselho da Comunidade. Em contrapartida, o segundo atua desde 1997 e foi escolhido pelo grupo pela sua experiência em diferentes cargos do Conselho e do Clube Agrícola. Atenuava-se a hierarquia estabelecida, mas de qualquer forma ambos estavam afiliados a diferentes organizações.

Embora tenhamos mencionado a Associação Integrada de Piripindeua, nossos esforços de análise neste artigo estão centrados na dinâmica das atividades do Clube Agrícola, do Clube de Mães e da Coordenação Regional, visto que ali encontramos dois tipos de evidências de reciprocidade (reciprocidade com retorno material e simbólico e com retorno espiritual), cuja estrutura central é o mutirão.

A reciprocidade com retorno material e simbólico, compreendido a partir das ideias de Polanyi (2000 [1944]) como um tipo de reciprocidade cujo retorno cria um tipo de laço ou vínculo que, além de estimular a produção de bens materiais e serviços (alimentos, assistência técnica e mão de obra), também promove a circulação de bens simbólicos (palavras, gestos, amizade etc.). O que ocorre neste caso está bem próximo da definição de reciprocidade direta mencionada por Sabourin $(2008$, p. 135) como "prestações materiais ou simbólicas desenvol- vidas entre dois indivíduos e dois grupos". No caso em estudo, as relações ocorrem entre pares de uma organização e entre estes e as famílias da comunidade.

Já a reciprocidade com retorno espiritual, analisada a partir da interpretação dos escritos de Mauss (1974 [1950]) como as relações que ultrapassam as fronteiras dos círculos dos humanos entre si, estendendo-se entre estes e deuses, espíritos dos mortos, animais e a natureza em geral. O doador pode receber o retorno a partir da ação de seres sobrenaturais. Como na reciprocidade indireta (Sabourin, 2008), neste caso a analise leva também em consideração a presença de um terceiro para o estabelecimento da retribuição. Os "[...] bens simbólicos não são devolvidos a quem os deu" [...] (Sabourin, 2008, p. 135-136), como descrito pelo autor, mas diferentemente não são passado a outro grupo. Sublinhamos o aspecto religioso dessa circulação "[...] que se evidencia nos sacrifícios, nas dádivas de palavras das rezas, etc." (Lanna, 2000, p. 178).

Em ambos os casos, diferentemente da troca no mercado, foi identificada a criação de uma obrigação, o que indica uma relação de reciprocidade. No primeiro caso, a retribuição ocorre de forma direta, enquanto no segundo recorre-se a uma divindade como uma terceira pessoa à qual e transferida a obrigação.

\section{RETORNO MATERIAL E SIMBÓLICO, UM ESTIMULO À PRODUÇÃO E SOBREVI- VÊNCIA DA FAMÍLIA}

Universo por excelência da reciprocidade com retorno material e simbólico, o Clube Agrícola foi fundado no início da década de 
1960, quando a Igreja Católica passou por profundas transformações e adotou a postura de assumir "[...] as formas de associação que o povo desenvolveu historicamente (por exemplo, o mutirão), sua maneira de relacionar-se com a natureza e com os demais homens" (Boff, 1980, p. 26). Como reflexo, foram formadas as Comunidades Eclesiais de Base (CEBs) na região do Nordeste Paraense ${ }^{5}$ por meio da Prelazia em Bragança ${ }^{6}$ no ano de 1958. Compunham o repertório de atuação as ações de evangelização, educação formal e formação profissional dos agricultores por meio da Rádio Educadora, com destaque para a formação de dirigentes ${ }^{7} \mathrm{de}$ Clubes Agrícolas.

Espaço predominantemente masculino, em 2012, a organização contava com aproximadamente 45 participantes, entre sócios e dirigentes (presidente, secretário e tesoureiro) que se reuniam todas as quartas feiras para a realização de atividades produtivas e recepção de visitantes. Ocasionalmente, as mulheres se reuniam no Clube de Mães para cozinhar para visitantes ou organizar eventos. A segmentação reforça papéis atribuídos aos homens como os responsáveis pela produção e pelas relações com terceiros na vida pública e, às mulheres, a reprodução, pondo em prática a divisão entre as esferas da produção e reprodução, conforme analisado por Hirata e Kergoat (2003) e Chiriac e Padilha (1982).
A reprodução da estrutura é fortalecida pela participação e socialização dos mais jovens, os rapazes no Clube Agrícola e as moças no Clube das Mães. Embora sejam considerados associados somente aqueles que já constituíram família, a participação de filhos e filhas que se integram aos trabalhos visa compensar as ausências dos pais. Essa prática se mantém por diferentes gerações.

As atividades do Clube Agrícola têm no mutirão a sua base e o evento consta da união de pessoas para efetuar trabalhos comuns que podem beneficiar uma família ou todo o grupo da vizinhança (Caldeiras, 1956; Candido, 2001; Sabourin, 2006).

O clube agrícola comporta uma intensa rede de relações para a realização dos trabalhos por meio do mutirão que pode beneficiar a coletividade (todos os membros da comunidade que participam) e as necessidades individuais de uma família.

No caso do mutirão para a coletividade, o trabalho ocorre para a formação da roça (feijão, milho, mandioca) e da piscicultura, ambas as atividades são realizadas em lotes que pertencem a todos os sócios. A novidade do compartilhamento da terra foi introduzida pela Igreja Católica com o objetivo de realizar a assistência técnica, pois nessas áreas são repassadas as orientações de instituições responsáveis por esse tipo de serviços. O trabalho na roça ocorre às quartas feiras e obedece a seguinte se-

5 Documento consultado na Diocese de Bragança no dia 3/1/2013 com a denominação VII Parte: JUBILEU DE PRATAS DAS CEBS.

6 Vale ressaltar que a Prelazia surgiu no início do século XIX na cidade de Bragança, recebendo em diferentes períodos históricos as denominações: Paróquia de Bragança (1906 a 1930), Prelazia de Gurupy, depois chamada Prelazia do Guamá (1934 a 1980$)$ e Diocese de Bragança (1980 até os dias atuais) (CONCEIÇÃO, 2002). A longa data de existência dessa instituição no Pará permitiu a sua consolidação e interferência nas localidades próximas a Bragança

7 Agricultor responsável pela mobilização da comunidade com fins de realizar o mutirão para praticar os novos aprendizados. 
quência: todas as etapas de produção são realizadas coletivamente (derrubada, plantio, capina e colheita); o momento das refeições e pausa do trabalho é compartilhado, estendendo ainda mais o momento de estar junto. Por fim, ali são distribuídos os alimentos produzidos. Uma parte é destinada aos sócios e a outra é vendida e os recursos gerados são utilizados para os investimentos nos empreendimentos coletivos. Este caso pode ser considerado uma relação binária de compartilhamento de trabalho e de recursos $^{8}$.

A piscicultura exige um trabalho diário que é realizado por equipes que se revezam entre as atividades diurnas (alimentar os peixes, cuidados com o tanque e receber equipes de técnicos que auxiliam no empreendimento) e noturnas (vigiar o local por conta da frequência dos roubos dos peixes e dos equipamentos. Para isso, os membros do Clube Agrícola montam equipes que se revezam, organizadas a partir de uma escala semanal de maneira que não comprometa o desenvolvimento das atividades individuais dos sócios. Ao mesmo tempo em que produtos são divididos entre as famílias dos membros do clube para garantir uma pequena parte da dieta alimentar, os recursos oriundos da venda subsidiam circularmente outras atividades, como a compra de alevinos e a realização de festas. Ocasionalmente, os recursos da venda de um boi podem garantir a ração necessária para a finalização da engorda dos peixes, que, uma vez vendidos, proporcionam recursos para comprar dois bezerros. Como no caso an- terior, trata-se de uma relação binária de compartilhamento de trabalho e de recursos.

A união nos lotes comunitários gera a continuidade do mutirão realizado historicamente pelo grupo, antes da chegada da Igreja Católica. Os integrantes do clube, muitas vezes, são mobilizados para atender as dificuldades de uma família que está em apuros ou pela falta de mão de obra, ou por uma situação de doença. Em uma ocasião da pesquisa de campo, os sócios foram socorrer um dos integrantes que contava com pouca mão de obra para a fabricação da farinha, já que uma parte dos membros da família dele dividia o tempo para a realização de atividades ligadas ao serviço público. A ajuda tinha um caráter de urgência, também porque o dia seguinte era um dia santo e os agricultores não podiam dedicar tempo ao trabalho, correndo o risco da mandioca estragar. Identificamos neste caso uma reciprocidade binária de "cara a cara" (dádiva e contradádiva).

Quanto aos rituais do mutirão analisados na literatura, o caso em estudo apresenta semelhanças e diferenças. A semelhança se refere ao hábito de compartilhamento das refeições no dia de trabalho na roça, prática que tem favorecido a relação entre membros do Clube Agrícola e do Clube de Mães a partir dos papéis tradicionais, pois as sócias preparam o almoço para os agricultores que se ocupavam com a roça. A diferença central com casos relatados na literatura aparece na ausência do caráter festivo do mutirão, situação interpretada a partir da

8 Sabourin $(2009$, p. 67) explica as estruturas elementares da reciprocidade e afirma que “a ajuda mútua corresponde a pelo menos três tipos de estruturas elementares de reciprocidade". a) a reciprocidade binária; b) o compartilhamento de trabalho ou recursos que pode ser também unilateral; c) a reciprocidade em forma de estrela. Estas estruturas que foram sistematizadas por Temple produzem sentimentos e valores por meio das relações humanas relacionadas a cada categoria de estrutura (TEMPLE, 2003, p.188-193). 
leitura da obra de Esterci (1987) como herança de um passado de conflitos pela posse de terra. Para a autora,

Situações de conflito, quando o campesinato se vê ameaçado de perder suas terras, são favoráveis à implementação de mutirões no sentido de autodefesa do grupo e, então o caráter festivo pode ser substituído pelo caráter político da cooperação (...) (Esterci, 1987, p. 196).

A autora trata de um caso com semelhanças com a experiência de Santa Ana. Os agricultores viviam no povoado Santa Terezinha, Mato Grosso, e aí empreenderam um projeto denominado de "roça comunitária", o qual foi implementado por intermédio de um padre nos anos 1960, num contexto de disputa pela posse da terra. O modelo de mutirão era imposto pela Igreja Católica e, por ser diferente daquele tradicionalmente realizado pelos agricultores, não era assimilado pelo grupo. Uma posseira disse: "foi uma ideia do padre Francisco para ver se dava certo trabalhar no mutirão" (Esterci, 1987, p. 191).

O relato permite a percepção da artificialidade e das contradições formadas a partir do convívio de uma estrutura elaborada por um especialista religioso (o padre) com aquelas formadas por agricultores que têm uma religiosidade própria (Wolf, 1976). Por um lado, reside aí a ausência do caráter festivo do mutirão. Por outro, as experiências nos indicam que o mundo do especialista e do agricultor ora podem ser vistos como opostos, ora podem conviver lado a lado, como indica a experiência em análise, a qual os agricultores optam por manter as organizações propostas pela Igreja Católica até os dias atuais.
Certamente, isso ocorre porque naquele caso a coexistência entre os mundos era garantida pela necessidade da posse da terra que, uma vez conquistada, deixou à vista as contradições. Já neste caso, a participação no clube se complementa com o trabalho individual e com outras dimensões da vida, economia, lazer, religião.

O Clube Agrícola tem influenciado na circulação de bens materiais e no recebimento de apoio de entidades externas. No entanto, sendo o mutirão compreendido como uma estrutura de reciprocidade (Sabourin, 2009), o que está em jogo aqui é o estabelecimento de laços sociais, refletido pelo prazer em estar juntos em detrimento dos ganhos econômicos. Por mais que houvesse a previsão de efetivar sanções para os agricultores que faltassem ao mutirão, os sócios do clube (que recebiam a doação) decidiram por não efetivá-las (estavam livres para doar) e, mesmo assim, os envolvidos decidiam evitar faltar (os participantes sentiam uma obrigação espontânea em colaborar).

Mais do que obter bens materiais, a escolha por cooperar pode ser explicada pela importância em manter a tradição e memória do passado, observada quando se sabe que, mesmo que o Clube tenha uma sede, não se alterou a opção de realizar encontros debaixo da sombra de uma árvore, tal qual ocorria tradicionalmente nas ações das CEBs na Amazônia (Boff, 1980). Dessa forma, os membros do grupo discutem problemas e estabelecem redes com organizações externas. Além disso, nos dias de trabalho buscam intensificar a união quando do compartilhamento das refeições, seja para manter uma prática realizada desde a criação da organização, seja pelo fato de que "eles gostam de viver junto, de fazer coisas juntos, por estar junto" (Mota et al., 2011, p. 225). 
Esse comportamento gera laços de amizade, que influenciam no hábito da realização do mutirão quando um dos sócios apresenta dificuldades para a realização da produção individual. Comumente, existe a escassez de mão de obra. Por um lado, o socorro aos amigos pode ocorrer com a doação de trabalho que, geralmente, não era solicitado pelo beneficiado, fenômeno caracterizado por Caldeiras (1956) como reciprocidade espontânea. Por outro lado, pode haver a solicitação de ajuda. Este é o caso de um dos agricultores que costuma solicitar o empréstimo da casa de farinha de outro agricultor quando a sua está impossibilitada devido à falta de água para preparar os tubérculos da mandioca para o processamento da farinha d'água, muito consumida no Pará.

Tanto no mutirão realizado para efetuar trabalhos comuns aos sócios do clube, quanto naqueles que podem beneficiar uma família, a retribuição ocorre para além do campo da distribuição da produção. Há uma espécie de competição silenciosa, na qual os integrantes rivalizam-se na doação de dádivas ofertadas para o funcionamento do mutirão e para a ajuda aos "companheiros" de trabalho. Aquele (ele e sua família) que mais doa usufrui de maior prestígio e poder político e poderá assumir o papel de "notável", sendo escolhido e escolhendo dirigentes para as organizações.

Enfim, o que circula entre os sócios do Clube Agrícola possui um duplo significado: material, porque garante o sustento da família; e simbólico, porque apresenta uma complexidade quanto à liberdade e à obrigação de contribuir, bem como à valorização da pessoa na vida em comunidade.

\section{RETORNO ESPIRITUAL, UNIÃO PARA ATIVIDADES RELIGIOSAS}

A reciprocidade com retorno espiritual é praticada no Clube de Mães e na Coordenação Regional. Nesses casos, ao contrário do que ocorre com a reciprocidade com retorno material e simbólico, há uma dificuldade maior da apreensão do fenômeno em análise, pois esse é o campo do espiritual e das crenças, no qual ocorre a propagação de sentimentos e a circulação de bens simbólicos que, muitas vezes, estão para além da percepção visual.

O Clube de Mães foi fundado no início dos anos 1960, no mesmo contexto da criação do Clube Agrícola. Trata-se de uma organização formada por mulheres que, na sua origem, foram mobilizadas por uma liderança local para realizar atividades de corte e costura, bordado, artesanato e arte culinária, assim como aprender noções de saúde, higiene do lar e hortas caseiras ${ }^{9}$, atividades consideradas pertinentes à esfera doméstica. A atribuição assemelha-se também a uma divisão que era praticada nos serviços de assistência técnica e extensão rural em voga nos anos 1960, na qual aos profissionais homens (extensionistas) e mulheres (economistas domésticas) competiam orientar a "modernização" nas esferas da produção e reprodução, respectivamente. Contrariando as observações recentes, constatamos que as mulheres participavam junto com os homens do mutirão para a produção agrícola mediante a demanda por mão de obra.

O Clube de Mães tem 22 associadas, que se reúnem na sede, construída no ano de 2008, para organizar os eventos festivos, dentre os

9 Documento consultado na Diocese de Bragança no dia 3/1/2013 com a denominação VII ${ }^{\circ}$ Parte: JUBILEU DE PRATAS DAS CEBS. 
quais a festa da padroeira da comunidade, Santa Ana. Nos dias que antecedem a festa, elas se reúnem para planejar e é comum dividirem o grupo em equipes que, por ocasião da pesquisa, denominavam-se de: "equipe do bolo", "equipe da ornamentação", “equipe do frango”, dentre outras. No período da festa, elas preparam os alimentos a serem vendidos. Em todas as ocasiões, elas se fazem acompanhar pelas crianças (meninos e meninas) que se alternam entre a "ajuda" aos adultos e as brincadeiras.

Praticamente inexiste a colaboração das mulheres do Clube de Mães no trabalho coletivo da agricultura, à exceção da preparação do almoço para os integrantes do Clube Agrícola por uma delas. Para isso, ela conta com a ajuda de duas filhas para preparar o almoço nas ocasiões que tem mutirão. Em certa ocasião, elas não puderam preparar a refeição e os homens recorreram à ajuda de uma vizinha. Eles disseram que neste dia a refeição saiu em tempo hábil, mas não estava tão saborosa. A ambiguidade do elogio (tempo hábil para uma, comida saborosa para outra) expressa a retribuição via agradecimento ao trabalho de todas. Tal iniciativa aparece como uma forma de valorizar os participantes que contribuem rotineiramente com o mutirão (Sabourin, 2006).

A experiência descrita assemelha-se àquela analisada por Chiriac e Padilha (1982) em pesquisa sobre Clubes de Mães estimulados pela Igreja Católica no Sudeste Brasileiro. As autoras observam que, embora as atividades reproduzam aquelas realizadas na esfera privada do lar, nesses espaços as mulheres podem partilhar momentos de lazer e dividir problemas. Assim, a possibilidade de participar da organização pode ser considerada como uma retri- buição, uma vez que estamos em um ambiente propício para criar vínculos de amizade, o qual faz circular palavras de consolo e estímulo para enfrentar dificuldades. Além disso, é a oportunidade de participação em um espaço semipúblico, já que a festa da padroeira mobiliza toda a comunidade, visitantes e parentes que chegam. Os integrantes das demais organizações se ocupam com os ritos da procissão, com os reparos da estrutura física do salão comunitário (carpintaria, pintura, construções de barracas) onde ocorre o evento e com a obtenção de produtos para o leilão.

Atuando para além da localidade, a Coordenação Regional, organização fundada oficialmente na década de 1990, é composta por lideranças que representam as suas respectivas comunidades originalmente formadas sob a influência da Igreja Católica nos anos 1970. Todas elas têm nomes de santos e situam-se nas circunvizinhanças, dentro do assentamento Itabocal. São elas: Santa Rita, Santo Antônio, São Francisco, São Paulo, São Pedro, Nossa Senhora de Nazaré, Santa Ana do Jaraquara, Rainha da Paz e São José. Não obstante a sua mais recente fundação, as funções da Coordenação Regional existem desde 1950.

Embora a data da criação seja recente, tal como ocorre com as demais organizações, existe uma preservação da memória do passado local. Todos os integrantes atuam como coordenadores da comunidade nas localidades onde moram. Essa função é uma das mais antigas, criada em 1950, antes mesmo dos clubes.

As lideranças da Coordenação Regional são na sua maioria homens e deles é exigida maior aproximação com a Igreja Católica, seja pela preparação nos sacramentos (batismo, pri- 
meira comunhão, crisma), seja por atuarem em celebrações litúrgicas como Ministros da Eucaristia. Essa aproximação com o sagrado reflete nas ações dos participantes, uma vez que são eles que promovem a festa de Corpus Christi e coordenam as ações de apoio a pessoas que passam por dificuldades.

Do mesmo modo que no Clube Agrícola, o mutirão é a estrutura central das ações cujas finalidades são religiosas e de solidariedade. As atividades do grupo são programadas em reuniões quinzenais que ocorrem na casa do coordenador regional. $\mathrm{Na}$ ocasião da pesquisa, um mutirão foi organizado para a construção de uma casa para uma família cujos membros estavam em estágio terminal por conta de uma grave doença, o que pode ser considerado, segundo Sabourin (2009, p. 67), um caso de reciprocidade unilateral (compartilhamento unilateral). Foi também programada a coleta de recursos financeiros nas comunidades para alimentar o gado do grupo que se encontrava em pastos individuais. Os animais eram destinados ao almoço festivo da festa religiosa quando seriam consumidos pelos fiéis na comemoração de Corpus Christi, que ocorre na Comunidade Santa Ana, por ser esta considerada o centro do assentamento Itabocal.

Em todas essas ações, não parecia haver explicitamente a expectativa de retorno pelas ações realizadas. Por um lado, pessoas eram ajudadas; por outro, a comunidade usufruía dos momentos de lazer ofertados nas festas religiosas. Ao observado, quanto maior é a aproximação e o envolvimento com o campo religioso do agricultor, maior a tendência para recusar a retribuição. Em um caso e em outro campo religioso, Candido constatou que os curandei- ros "Não aceitam dinheiro, alegando trabalhar para o bem dos outros; mas aceitavam presentes em espécie das pessoas que os procuravam em boa quantidade" (Candido, 2001, p. 183). É como se houvesse uma tentativa de demarcar diferenças, estando o dinheiro mais próximo do que representa as trocas de mercado e o presente mais coerente com os valores humanos como a fé e o agradecimento.

No caso da Coordenação Regional, são conteúdos da reciprocidade os símbolos e a relação com seres divinos. O esforço para realizar festas religiosas leva os agricultores a estabelecerem vínculos com Santa Ana e Jesus Cristo. São, assim, os santos da Igreja Católica introduzidos nos sentimentos da vida comunitária para retribuir as doações feitas no lugar daqueles que estavam impossibilitadas da devolução da ajuda recebida. Desse modo, as pessoas responsáveis pela procissão da padroeira tratavam de transmitir mensagens de agradecimentos para aqueles que contribuíam para a realização do festejo e afirmavam nos discursos que a doação será recompensada, não pelos fiéis, mas por Santa Ana e membros da Sagrada Família.

O céu inteiro está rezando para ti, o céu inteiro está olhando para ti, os santos. Aqui é apenas uma imagem, mas Santa Ana e São Joaquim com certeza estão rezando pelas nossas cozinheiras, estão rezando pelas aquelas que passaram a noite aí para acontecer essa festa, está rezando pela coordenação, estão rezando por aqueles que lutam, por esse povo.

Os santos não só eram citados em alusão às futuras retribuições da ajuda concedida em favor de terceiros, mas a eles eram concedidas festas e homenagens e, assim, fazem par- 
te das relações de reciprocidade. Nesse sentido, para os integrantes de todas as organizações, a cura de uma doença e o sucesso de uma colheita podem ser interpretados como retribuições divinas, concedidas por Jesus e Santa Ana em retribuição pela participação nas festas religiosas e pela ajuda concedida em benefício de pessoas em dificuldades.

As dádivas relacionadas aos santos podem ocorrer, principalmente, no mutirão em beneficio de uma família. Segundo constatou Candido: "Um velho caipira me contou que no mutirão não há obrigação para com as pessoas, e sim para com Deus, por amor de quem se serve o próximo; por isso, a ninguém é dado recusar auxílio pedido" (Candido, 2001, p. 68).

No que se refere ao vínculo estabelecido diretamente com o santo, outras interpretações são possíveis. Segundo Forman (1979), existe uma tendência para interpretar o comportamento religioso do agricultor a partir dos parâmetros da troca mercantil. Nessa perspectiva, ou a relação entre santos e agricultores equivalem aos princípios do clientelismo e os santos aparecem como um patrão, que mantém o agricultor subordinado por meio da troca de favores (promessas); ou os agricultores são vistos como indivíduos que buscam otimizar resultados e, tal como num mercado competitivo, escolhem e até substituem o santo padroeiro por outro mais poderoso e/ou especializado para o pedido. Podem ainda estrategicamente pagar a promessa somente depois de ver cumprido o pedido feito ao santo. Um exemplo citado pelo autor ilustra bem a negociação: "se você fizer tal coisa por mim, eu farei...” (FORMAN, 1979, p. 278).

Forman (1979) apresenta argumentos que nos levam a acreditar ser difícil entender o campo religioso com as mesmas lentes utilizadas para compreender o campo secular. Os vínculos entre um e outro parecem ser distintos e incompatíveis. Nas relações clientelistas o vínculo patrão-cliente ocorre por meio de contrato estipulado e, no caso dos santos e devotos, pela promessa estabelecida a partir de uma relação mais ampla, caracterizada pela expressão de fé, a qual não equivale à expressão de lealdade do clientelismo. Da mesma forma, nas trocas de mercado o vínculo é encerrado com o pagamento da dívida, enquanto entre santo e devoto ele é duradouro, tal como ocorre nas relações de reciprocidade (Godbout, 1998). Por mais que ocorra a transferência de devoção para um santo mais poderoso, o laço com o padroeiro não é rompido de maneira definitiva.

Concordamos com Forman (1979) quanto à possibilidade das duas interpretações, na medida em que o campo religioso pode ser pensado a partir de uma função de amortecer e preencher experiências humanas inevitáveis, como o sofrimento e a morte (Wolf, 1976), mas também sob o ponto de vista do campo secular, onde a religiosidade pode ser apropriada pelo agricultor para criar estratégias de sobrevivência diante da realidade de dependência que vive (Foster, 1963) e para legitimar o sistema de organização da agricultura familiar, no que se refere às especificidades da economia e estrutura familiar (Wolf, 1976).

\section{CONSIDERAÇÕES FINAIS}

O objetivo do artigo foi analisar as relações de reciprocidade entre os participantes das organizações dos agricultores familiares em uma comunidade rural, que habitam há mais de 
70 anos num assentamento de reforma agrária no Pará. Ali, como em outras localidades no Estado, o processo de acesso à terra iniciou-se pela posse, chamado a "época dos antigos", passando por situações de disputa até a regularização.

A condição de regularização, denominada de reforma agrária pelas instituições públicas, é localmente considerada a "época dos projetos" em associação com os diferentes serviços dotados pela reforma agrária.

Estimulados pelas ações das CEBs, várias organizações se instituíram com diferentes objetivos e recorte de gênero, a exemplo do Clube Agrícola, Clube das Mães e Coordenação Regional. Elas têm em comum o fato de abrigarem os que professam a fé católica e terem como uma das suas ações estruturantes o mutirão. Diferenciam-se pelo tipo de afiliados (se homens ou mulheres), pelo modo de funcionamento (frequência e intenção de encontros) e pelos propósitos (produção, organização de eventos ou apoio a terceiros).

As conclusões indicam que existem dois tipos de evidências de reciprocidade praticados pelos grupos, quais sejam: a reciprocidade com retorno material e simbólico e a reciprocidade com retorno espiritual.

A reciprocidade com retorno material e simbólico, vivenciada por excelência pelos afiliados ao Clube Agrícola estimula a produção que subsidiará tanto o aprovisionamento da família dos associados, quanto a própria estrutura que garante a existência do Clube, que é constituída por várias atividades que se reproduzem por meio do mutirão.

A reciprocidade com retorno espiritual, vivenciada pelos afiliados ao Clube de Mães e à Coordenação da Regional, se caracteriza pe- las relações entre as pessoas e as suas divindades que se consolidam para cada um por meio de bênçãos na colheita, na saúde e na vida em geral.

Metodologicamente, a identificação da reciprocidade com retorno espiritual somente é possível ser analisada quando levamos em consideração a circulação de bens espirituais e simbólicos (palavras, prestígio, amizade, etc.). A relação entre as pessoas e as suas divindades (Deus e Santa Ana) é persistentemente buscada pelo envolvimento de terceiros (os que são ajudados, socorridos).

Mesmo sem a presença da estrutura das CEBs, existe atualmente um esforço por parte dos agricultores para preservar ao máximo a estrutura de organização sugerida pela Igreja Católica no passado.

Trabalho recebido em 20/12/2013 Aprovado para publicação em 02/04/2014

\section{REFERÊNCIAS}

BOFF, Leonardo. O caminhar da Igreja com os oprimidos: do vale de lágrimas à terra prometida. Rio de Janeiro: Codecri, 1980. 252 p.

BOURDIEU, Pierre. Marginália. Algumas notas adicionais sobre o dom. In: Revista Mana, v. 2, n. 2, Rio de Janeiro, 1996a, p.7-20.

BOURDIEU, Pierre. Razões práticas: sobre a teoria da ação. Campinas: Papirus Editora, 1996b. 231 p.

CAILLÉ, Alain. Nem holismo, nem individualismo metodológicos: Marcel Mauss e o paradig- 
ma da dádiva. In: Revista Brasileira de Ciências Sociais, v. 13, n. 38, São Paulo, 1998, p. 5-37.

CALDEIRAS, Clovis. Mutirão: formas de ajuda mútua no meio rural. São Paulo: Companhia Editora Nacional, 1956. 222 p.

CANDIDO, Antônio. Os parceiros do Rio Bonito: estudo sobre o caipira paulista e a transformação dos seus meios de vida. 9. Ed. São Paulo: Duas Cidades: Ed. 34, 2001. 376 p. $<$ Original: Tese de doutorado de 1954, publicado em 1964>.

CHAYANOV, Alexander V. Sobre a teoria dos sistemas econômicos não capitalistas. In: SILVA, José Graziano da; STOLCKE, Verena (Org.). A questão agrária. Tradução: Edgar Afonso Malagodi; Sandra Brizola; José Bonifácio da S. Amaral Filho. São Paulo: Editora Brasiliense, 1981. p. 133-164.

CHIRIAC, Jany; PADILHA, Solange. Características e limites das organizações de base femininas. In: BRUSCHINI, Maria Cristina A; ROSEMBERG, Fúlvia (Org.). Trabalhadoras do Brasil. São Paulo: Editora Brasiliense, 1982. p. 19-203.

CONCEIÇÃO, Maria de Fátima Carneiro. Reprodução social da agricultura familiar: um novo desafio para a sociedade agrária paraense. In: HÉBETTE, Jean, MAGALHÃES, Sônia Barbosa; MANESCHY, Maria Cristina (Org.). No mar, nos rios e na fronteira: faces do campesinato no Pará. Belém: Editora da UFPA, 2002, p. 131-172.

ESTERCI, Neide. Conflitos no Araguaia: peões e posseiros contra a grande empresa. Petrópolis: Editora Vozes, 1987, 208 p.
FORMAN, Shepard. Camponeses: sua participação no Brasil. Tradução Maria Isabel Erthal Abdenur. Rio de Janeiro: Paz e Terra, 1979, $340 \mathrm{p}$.

FOSTER, George M. The dyadic contract in Tzintzun, II: patron-client relationship. In: American Anthropologist, v. 65, n. 6, Arlington, Dec. 1963, p. 1280-1294.

GODBOUT, Jacques T. Introdução à dádiva. In: Revista Brasileira de Ciências Sociais, v. 13, n. 38, São Paulo, 1998, p. 39-51.

GODBOUT, Jacques T. Le Don, la dette et l'identité. Montréal: Editions La Découverte; Editions du Boréal. 2000. 190 p.

HIRATA, Helena; KERGOAT, Danièle. A divisão sexual do trabalho revisitada. In: MARUANI, M.; HIRATA, H. (Org.). As novas fronteiras da desigualdade: homens e mulheres no mercado de trabalho. Trad. Clevi Rapkievicz. São Paulo: SENAC, 2003, p. 111-123.

HURTIENNE, Thomas. A agricultura familiar e o desenvolvimento sustentável: Problemas conceituais e metodológicos no contexto histórico da Amazônia. In: Revista Econômica do Nordeste, v 30, número especial, O Nordeste no novo milênio, Fortaleza, dez. 1999, p. 442467.

LANNA, Marcos. Nota sobre Marcel Mauss e o ensaio sobre a dádiva. Revista Sociól.Polít., 14, Curitiba, jun. 2000, p.173-194.

MAGALHÃES, Sônia Barbosa. Direitos e projetos: uma leitura sobre a implantação dos assen- 
tamentos no Sudeste do Pará. In: MARTINS, José de Souza (Coord.). Travessias: A vivência da reforma agrária nos assentamentos. Porto Alegre. Editora da UFRGS, 2003. p. 202-294.

MAUSS, Marcel. Ensaio sobre a Dádiva: forma e razão da troca nas sociedades arcaicas. In: Sociologia e antropologia, v II. São Paulo: Editora Pedagógica e Universitária, 1974, p. 183294 < Original: 1950>

MENDRAS, Henri. Sociedades camponesas. Tradução: Maria José da Silveira Lindoso. Rio de Janeiro: Zahar, 1978, 265 p.

MOTA, Dalva Maria da; FIGUEIRA, Maria Bárbara de Andrade; CASTRO, Dulcilene Alves; SOUSA, Glaucia Macedo; MAYER, Gustavo. "Aqui nós já era tudo conhecido"; sociabilidades em assentamento de reforma agrária no Pará. In: BERGAMASCO, Sonia Maria Pessoa Pereira; OLIVEIRA, Julieta Teresa Aier de; ESQUERDO, Vanilde Ferreira de Souza (Org.). Assentamentos rurais no século XXI: temas recorrentes. Campinas: FEAGRI/UNICAMP; São Paulo: INCRA, 2011. p. 209-226.

OLSON, Mancur. A lógica da ação coletiva: benefícios públicos e uma teoria dos grupos sociais. Trad.: M. D. C. Guerreiro; M. L. Faria. Ver. Téc. P. T. Pereira. Oeiras: Celta Editora, 1998. 168 p. <Original: $1965>$

POLANYI, Karl. A grande transformação: as origens de nossa época. Tradução: Fanny Wrabel. 2. Ed. Rio de Janeiro: Campus, 2000, 337 p. <Original: 1944>

SABOURIN, Eric. A ajuda mútua rural, entre intercâmbio e reciprocidade. In: ENCONTRO
DA REDE DE ESTUDOS RURAIS, 1, Niterói. Anais... Niterói: UFF, Rede de Estudos Rurais, 2006. 16 p. (CD)

SABOURIN, Eric. Marcel Mauss: da dádiva à questão da reciprocidade. In: Revista Brasileira de Ciências Sociais, v. 23 n. 66, São Paulo, fev. 2008, p. 131-139.

SABOURIN, Eric. Camponeses do Brasil: entre a troca mercantil e a reciprocidade. Tradução: Leonardo Milani. Rio de Janeiro: Garamond, 2009, 325 p.

TEMPLE, Dominique. Teoría de la reciprocidad. Tomo II. La economía de reciprocidad. La Paz: PADEP-GTZ, 2003. 506p.

VEIGA, Iran; ALBALADEJO, Christophe. A formação do território a nivel local e a emergência da ação coletiva: análises das trocas simbólicas em duas coletividades locais da região de Marabá, Amazônia Oriental. In: Agricultura Familiar: Pesquisa, Formação e Desenvolvimento, v.1., n.3, Belém, 2002, p. 41-77.

VELHO, Otávio Guilherme. Capitalismo autoritário e campesinato: um estudo comparativo a partir da fronteira em movimento. 2.Ed. São Paulo: DIFEL, 1979, 261 p.

WOLF, Eric R. Sociedades camponesas. Tradução: Oswaldo Caldeira C. da Silva. Revisão: Gilberto Velho. 2. Ed. Rio de Janeiro: Editora Zahar, 1976. $150 \mathrm{p}$.

ZALUAR, Alba. Exclusão e políticas públicas: dilemas teóricos e alternativas políticas. In: Revista Brasileira de Ciências Sociais, v. 12, n. 35, São Paulo, fev. 1997. 20 p. 